\title{
Binaural and temporal integration of the loudness of tones and noises
}

\author{
DANIEL ALGOM \\ John B. Pierce Foundation Laboratory, New Haven, Connecticut \\ Yale University, New Haven, Connecticut \\ and Bar-Ilan University, Ramat Gan, Israel \\ and \\ ATALIA RUBIN and LIOR COHEN-RAZ \\ Bar-Ilan University, Ramat Gan, Israel
}

\begin{abstract}
Subjects judged the loudness of tones (Experiment 1) and of bursts of noise (Experiment 2) that varied in intensity and duration as well as in mode of presentation (monaural vs. binaural). Both monaural and binaural loudness, for both types of signals, obeyed the bilinear-interaction prediction of the classic temporal integration model. The loudness of short tones grows as a power function of both intensity and duration with different exponents for the two factors (.2 and .3, respectively). The loudness of wide-band noises grows as a power function of duration (with an exponent of approximately .6) but not of sound pressure. For tones, binaural summation was constant but fell short of full additivity. For noises, summation changed across level and duration. Temporal summation followed the same course for monaural and binaural tonal stimuli but not for noise stimuli. Notwithstanding these differences between tone and noise, we concluded that binaural and temporal summation are independently operating integrative networks within the auditory system. The usefulness of establishing the underlying metric structure for temporal summation is emphasized.
\end{abstract}

The integration of acoustic stimulation over time and the integration of stimulation over the two ears depict two widely documented auditory processes that display energy-dependent properties, at least for threshold. For both types of summation, loudness depends on the total amount of energy in the stimulus and is independent of how the energy is distributed over time or across the two ears (e.g., Babkoff \& Algom, 1976; Hughes, 1938). Moreover, both temporal and binaural summation vary with the type (tone vs. noise) and level (threshold vs. suprathreshold) of the stimulus (e.g., Algom, Adam, \& CohenRaz, 1988; Algom \& Babkoff, 1984; Algom \& Marks, 1984; Marks, 1980). Despite the obvious similarities in operation characteristics, these two energy-integrating networks in audition have been studied independently, using mutually exclusive types of stimulation. In the present study, we report the results of a combined investigation of the two phenomena. We asked to what extent, if any, integration of acoustic energy over time interacts with the integration of stimulation over the two ears. Do the rules that govern binaural summation change when the signals undergo temporal integration? Conversely, does the

\footnotetext{
Preparation of this paper was supported by NIH Grant NS21326 to Lawrence Marks, whose generous assistance and valuable comments are gratefully acknowledged. We also thank Robert Melara for his most helpful comments on an earlier version of this manuscript. Barbara Faulkner and Elise Low provided skillful assistance at various stages of the completion of the manuscript. Correspondence should be addressed to Daniel Algom, John B. Pierce Foundation Laboratory, 290 Congress Avenue, New Haven, CT 06519.
}

course of temporal integration differ for monaurally and binaurally presented stimuli? The present experiments enabled us to answer these questions by directly comparing temporal and binaural integration for the same suprathreshold stimuli.

\section{Binaural Summation of Tones and Noises}

Several experiments have examined binaural summation at threshold. For both tones and noises, the binaural threshold is lower than the monaural threshold, and the average difference is about $3 \mathrm{~dB}$ (e.g., Babkoff \& Algom, 1976; Chocholle, 1962; Hellman \& Zwislocki, 1963; Hughes, 1938; Shaw, Newman, \& Hirsh, 1947). Measurements of suprathreshold binaural summation reveal significantly greater binaural gains (when referred to soundpressure levels), indicating that it is loudnesses, rather than energies, that add (e.g. , Levelt, Riemersma, \& Bunt, 1972; Marks, 1979b). For pure tones and narrow-band noises, the results are consistent with a model of linear summation. The estimates of loudness of a binaurally presented signal approximate the sum of the loudness estimates of the left and right ear components. A binaural sound is, on the average, twice as loud as a monaural sound of the same sound-pressure level (SPL) (Algom \& Marks, 1984; Hellman \& Zwislocki, 1963; Levelt et al., 1972; Marks, 1978, 1979a, 1979b, 1980, 1987). To equal the loudness of a binaural tone, a monaural tone has to be $10 \mathrm{~dB}$ greater which, on the sone scale (i.e., loudness increases as the .6 power of sound pressure), corresponds to a doubling of loudness (S. S. Stevens, 1956). Although 
Scharf \& Fishken (1970) also found that the ratio of binaural to monaural loudness is constant, their results suggest less than complete summation.

For wide-band noise stimuli, on the other hand, the binaural-monaural ratio increases with increasing sound pressure (Algom et al., 1988; Irwin, 1965; Marks, 1980, 1987; Reynolds \& S. S. Stevens, 1960; Scharf, 1968; Scharf \& Fishken, 1970). Although Reynolds and Stevens (1960) concluded that the loudness of both monaural and binaural noise stimuli grows as a power function of sound pressure (but that the exponents differ), Scharf and Fishken (1970) and Marks (1980), as well as the majority of other investigations (see Scharf, 1978, for a review), have reported psychophysical functions for noise that are not power functions of sound pressure.

\section{Temporal Summation of Tones and Noises}

At threshold, the ear integrates the acoustic energy of a sinusoidal signal linearly up to a critical duration of about $250 \mathrm{msec}$; that is, in this range, a tenfold increase in duration results in a decrease in the signal intensity necessary for threshold by $10 \mathrm{~dB}$ (Algom \& Babkoff, 1978; Algom, Babkoff, \& Ben-Uriah, 1980; Garner \& Miller, 1947; Watson \& Gengel, 1969). For broad-band noise stimuli, however, only partial integration has been found, with a representative value of a 7- $\mathrm{dB}$ change in threshold for a tenfold change in duration (Babkoff \& Algom, 1976; Garner, 1947; Miller, 1948; Penner, 1978). For suprathreshold levels of stimulation, not only are the data sparse, but there appear to be some puzzling discrepancies. Some studies have shown that intensity has to be decreased by 10 to $20 \mathrm{~dB}$ for each tenfold increase in duration (Algom \& Marks, 1984; Small, Brandt, \& Cox, 1962; J. C. Stevens \& Hall, 1966; see also J. C. Stevens, 1976), whereas one study reported much steeper slopes (McFadden, 1975). Critical durations seem even more variable, encompassing, at times, ranges of over $1: 3$ or 1:4 (Algom \& Marks, 1984; see also the summary of results by Scharf, 1978). In fact, the very existence of a critical duration for suprathreshold loudness has been questioned (J. C. Stevens \& Hall, 1966; see also McFadden, 1975).

In any case, threshold and suprathreshold data alike may be described in terms of Garner's (1947) well-known general equation, $I \times t^{a}=C$, where $I$ denotes stimulus power, $t$ is duration, and the exponent $a$ is the slope of the line (reciprocity function) relating $\log I$ to $\log t$. $C$ represents a constant criterion loudness response such as threshold. Simple tradeoff between intensity and time $(a=1)$ exists for threshold tonal stimuli only. Threshold noise stimuli yield partial summation $(a<1)$, whereas suprathreshold integration usually gives supersummation $(a>1)$. Again, despite such summary values, no universal agreement has yet been found on the exact size of the critical duration, especially for suprathreshold stimuli, or on the exact nature and slope of the trading function (see Algom \& Babkoff, 1984, and Scharf, 1978, for recent reviews).

\section{Binaural and Temporal Summation Combined}

As noted, no experiment has been reported that directly compares monaural and binaural temporal integration in the suprathreshold range. Their combined resolution, though probably more complicated than at threshold (see Babkoff \& Algom, 1976), should give a more comprehensive account of their underlying auditory processes.

\section{EXPERIMENT 1 TEMPORAL INTEGRATION AND BINAURAL SUMMATION OF PURE TONES}

\section{Method}

Subjects. Ten subjects ( 7 females) with a mean age of 23 years (range: 20 to 29 years) participated in the experiment. They reported having no major hearing problems. All subjects were screened for normal hearing at frequencies of 1000,2000 , and $4000 \mathrm{~Hz}$, and were required to have monaural thresholds that did not differ by more than $2 \mathrm{~dB}$ at $2000 \mathrm{~Hz}$ across the two ears (method of limits). Four of the subjects had previous experience with the method of magnitude estimation, although not necessarily in judging loudness. Otherwise, all subjects were naive with regard to the experiment.

Apparatus. The 2000- $\mathrm{Hz}$ signal from a Heathkit 16-72 generator was gated and timed, and was then split into channels for the left and right ears. All stimuli were trapezoid-shaped, with 1-msec rise/fall times. The signal in each channel could be attenuated independently before being fed to a matched set of headphones (AKG-250A). Frequency and duration were monitored by a Monsanto $120 \mathrm{~A}$ counter-timer. Signal intensity was calibrated in an artificial ear by a Brüel and Kjaer precision sound-level meter (Model 2204).

Procedure. The subject sat in a sound-shielded booth (Medtechnic Silent Cabin). Five different levels of sound pressure $(30,40,50$, 60 , and $70 \mathrm{~dB}$ ) were combined factorially with six different durations $(16,32,64,128,256$, and $512 \mathrm{msec})$ to produce 30 different stimuli. These stimuli were presented both monaurally to each subject's right ear and binaurally, producing 60 different stimuli in all. The stimuli were presented one at a time to the subject for judgment. Each subject received two replicates of the entire threedimensional [SPL $(5) \times$ duration $(6) \times$ mode of presentation (2) $=60$ member] matrix in a session and served in two sessions (separated from one another by at least 1 day), thus giving four judgments per stimulus in all. The order of presentation of the stimuli was irregular and was different for each subject (orderly sequences that occasionally arise in random selection were intentionally avoided).

The method was free magnitude estimation. The subjects were instructed to assign to the first stimulus whatever number seemed most appropriate to represent its loudness, and to assign numbers, in proportion, to succeeding stimuli. If no sound was heard, the subject was to assign the number zero. The subjects were told that they could use whole numbers, decimals, and fractions as needed. In addition, they were instructed to disregard the apparent location or length of the stimuli and to judge only their loudness. The subjects made their judgments verbally, communicating with the experimenter via intercom.

\section{Results and Discussion}

Metric structure: The integration of time and intensity onto loudness. The magnitude estimates of loudness given to each stimulus were averaged geometrically, and these means are plotted in Figure 1 as a function of the SPL delivered to the right ear. The parameter is duration; each contour represents tones exposed for a differ- 


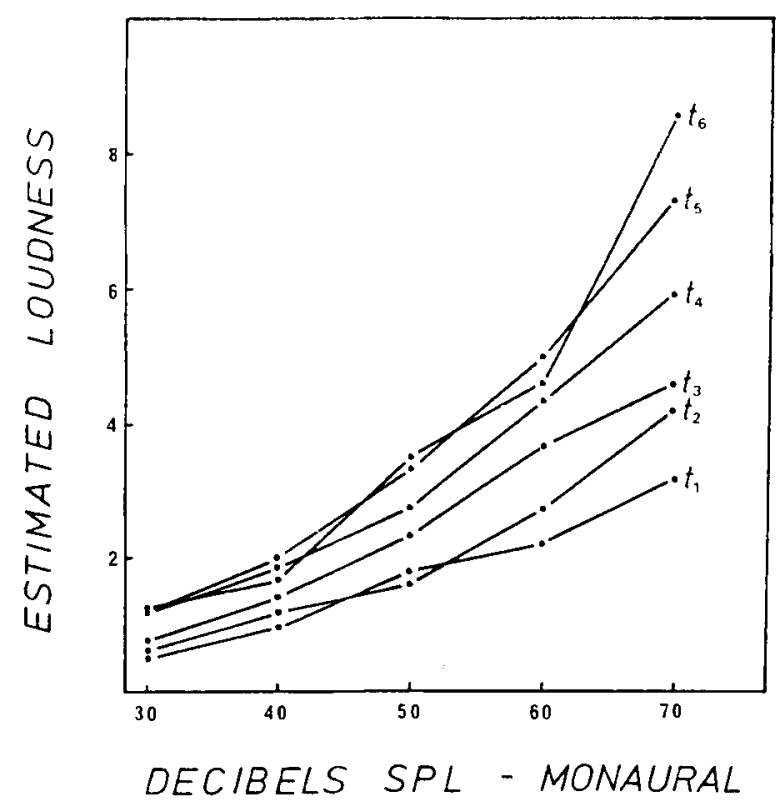

Figure 1. Monaural temporal integration. The average magnitude estimates of loudness plotted as a function of the sound-pressure level (SPL) delivered to the right ear. The parameter is duration; each contour represents tones exposed for a different constant duration $\left(t_{1}-t_{6}=16,32,64,128,256\right.$, and $\left.512 \mathrm{msec}\right)$.

ent constant duration. Assuming that (1) a multiplicative model is operating on the psychological representations of time and intensity transforming them onto loudness, and (2) an appropriate (linear) judgment function exists for the magnitude-estimation response, the curves in Figure 1 should diverge. The classic temporal integration model $(I \times t=C)$ implies that when durations are held constant, as in Figure 1, differences in loudness increase linearly with increasing SPL. The loudness estimates are plotted on a linear scale to make evident the metric implication of the classic multiplicative model for temporal integration: divergent interaction that is approximately bilinear.

Perhaps the most striking feature of this family of functions is their tendency to diverge from a common origin at the lower left. There is a systematic change in the SPL separating the functions from one another. The complementary plot of binaural presentations appears in Figure 2. Although there appear to be some small departures from monotonicity, these data, as well as the monaural data, seem to obey the implications of the model under test fairly well.

It is possible to subject the bilinear pattern implied by the multiplying rule to a more rigorous visual test (beyond the mere divergence nicely illustrated in Figures 1 and 2). To that end, we first calculated the marginal means for each level of the $2000-\mathrm{Hz}$ tone; this was accomplished by averaging the data across the six values of stimulus duration. Then the magnitude estimates were plotted against the marginal means in graphs analogous to those of Figures 1 and 2. These are the test plots. If the mul- tiplicative model holds, then all of the functions in the test plots should be straight lines (allowing for variability around the average points) with slopes that grow systematically larger. Indeed, the slopes derived from the data in Figures 1 and 2 formed, in each case, the expected diverging fan of straight lines. Thus, the results support an underlying multiplicative rule of integration of both monaural and binaural stimulation. ${ }^{1}$

Binaural summation and loudness as a function of pressure. Given a factorial design of the type used in these experiments and results consistent with bilinearity in the response domain, the marginal means provide valid estimates of the scale values (Anderson, 1974, 1981, 1982). Figure 3 presents these calculated scale values for monaural and binaural presentations as a function of SPL. These functions were produced by averaging across the different durations in the two data matrices.

The fits to the power functions (straight lines in the double logarithmic coordinates) are excellent ( $r^{2}=.985$ for the monaural function and .996 for the binaural function). The slopes (exponents of the power functions) are .36 and .42 , respectively. That the loudness functions are closely (though, perhaps, not fully) parallel can be made even more apparent by excluding the lowest $(30-\mathrm{dB})$ value from the monaural data set. (Failure of complete temporal integration at the longest duration for monaural stimulation probably affected judgments at this low SPL; see also Figure 5, below.) The truncated function is a bit steeper: the slope is .39 , supported by an even better fit $\left(r^{2}=\right.$ .989). Although these slopes are notably smaller than the .6 of the sone scale, they are by no means unusual within the framework of supraliminal temporal summation research. Three comparable studies (Algom \& Marks, 1984;

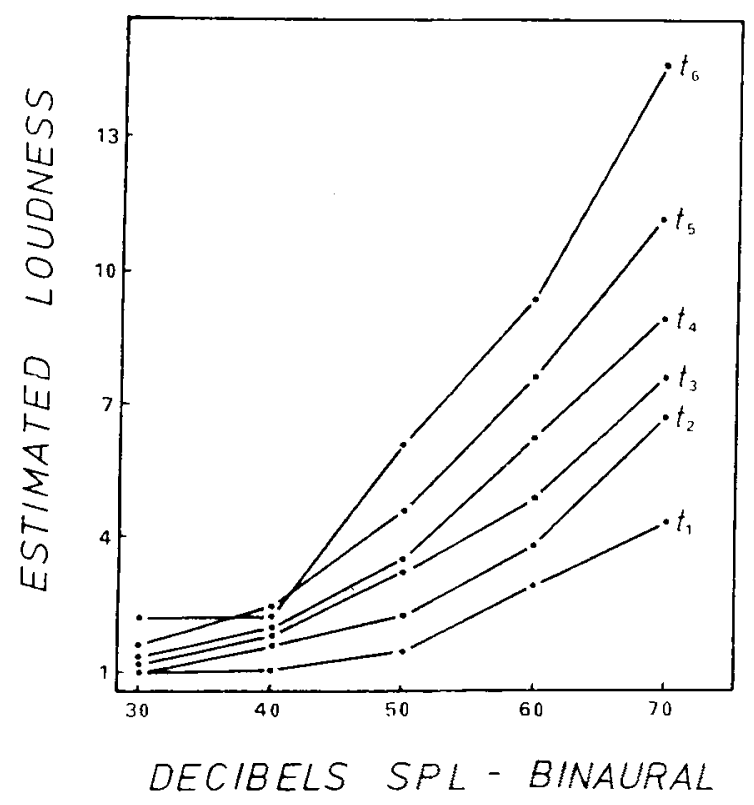

Figure 2. Binaural temporal integration. Same as Figure 1, for tones delivered to both ears. 


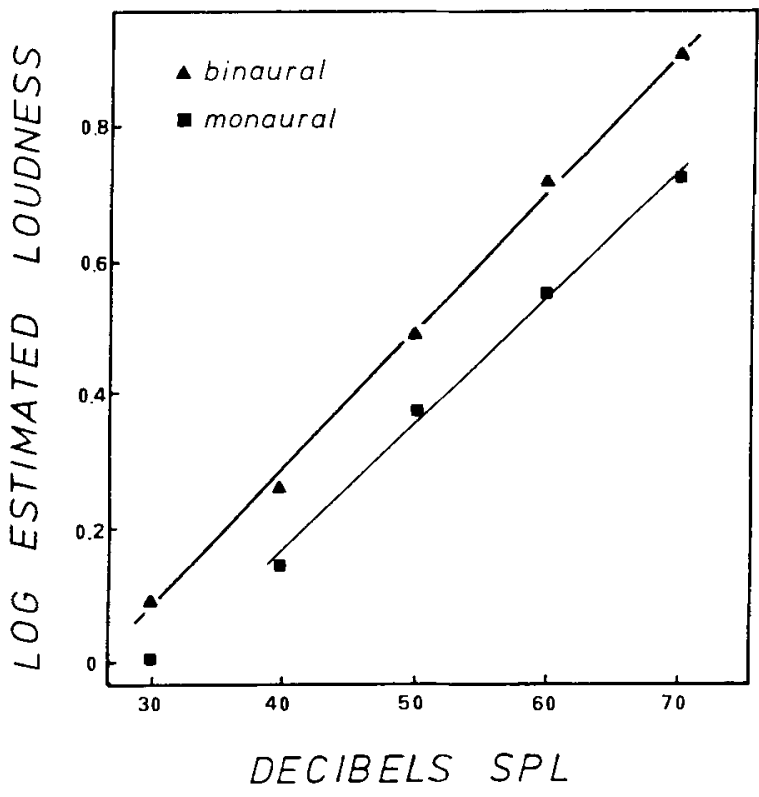

Figure 3. Binaural summation of loudness as a function of soundpressure level (SPL). Average loudness functions of binaural and monaural stimuli derived from the marginal means of the data plotted in Figures 1 and 2.

McFadden, 1975; J. C. Stevens \& Hall, 1966) yielded average magnitude-estimation exponents of $.46, .40$, and .54 (noise), respectively. The smaller exponents in the present study may stem from greater difficulty in judging stimuli that vary in duration and loci as well as intensity (Algom \& Marks, 1984; J. C. Stevens \& Hall, 1966; S. S. Stevens \& Greenbaum, 1966).

Binaural summation can be assessed from inspection of the horizontal separation between the monaural and the binaural loudness functions. Complete binaural summation implies that a sound presented to two ears should be just twice as loud as the same sound presented to one ear. According to the equation for sones, for example, loudness doubles with a 10-dB increase in sound pressure. Given the sone scale, it follows that a monaural stimulus must be $10 \mathrm{~dB}$ greater than a binaural stimulus for them to appear equally loud, as demonstrated by Algom and Marks (1984) and Marks (1978, 1979a, 1979b, 1980). Figure 3 gives a lower value for the binaural gain; at all but the lowest levels of sound pressure, the difference separating the binaural and monaural functions is about $7 \mathrm{~dB}$.

Most likely, the results of this experiment are commensurate with only partial summation of loudness across the two ears. ${ }^{2}$ Although Algom and Marks (1984) and Marks $(1978,1979 a, 1979 b)$ demonstrated linear additivity and a binaural gain of about $10 \mathrm{~dB}$ for tones, other studies have similarly indicated less than complete summation of around 7 dB (Caussè \& Chavasse, 1942; Scharf, 1969; Scharf \& Fishken, 1970; see also Irvin, 1965). In fact, Marks has also obtained less than complete summation in a couple of experimental conditions (e.g., Marks, 1979b, p. 270; Marks, 1980, Experiment 5). That summation was systematically less than perfect is also clear from inspection of Table 1, which summarizes the ratios of equal SPL binaural and monaural loudnesses. On the average, the subjects judged a sound heard with two ears as 1.5 times as loud as a sound of the same intensity heard with one ear. Similar binaural-monaural ratios of 1.7:1, 1.65:1, and 1.5:1 were obtained by Scharf and Fishken (1970), Jankovic and Cross (1977), and Marks (1980), respectively. No systematic effect either of duration or of pressure is evident in the calculated ratios. Rescaling the present data to an exponent of .6 (i.e., "correcting" the response scale to sones) increases the amount of binaural loudness summation (the binaural ratio becomes 1.84:1) but does not suffice to make the data fully additive. However, (small) subadditivity is apparently a common result with tones.

Binaural summation and loudness as a function of duration. Figure 4 shows how loudness grows as a function of duration for both monaural and binaural presentations. These functions were produced by averaging across the different SPLs in the data matrices.

It is clear that loudness grew approximately as a power function of the duration of the tone for both modes of presentation. The straight-line segments have slopes of .31 (binaural function, $r^{2}=.980$ ) and .23 (monaural function, $r^{2}=.930$ ). It is also clear, however, that an increase in duration above $256 \mathrm{msec}$ brought about little, if any, change in loudness for the monaural condition. (No visible discontinuity-a critical duration-appears in the binaural data.) Therefore, a better description of the data can result from confining the power fit to only the first five monaural data points-those falling at or below the critical duration. This gives a slope of .27 with a greatly improved fit $(r=.977)$. Thus, over all except the longest duration, the monaural and binaural functions virtually parallel one another and have slopes in the vicinity of .29 (their geometric average). This exponent differs from the exponents for loudness as a function of pressure obtained earlier. Although the absolute values differ somewhat, J. C. Stevens and Hall (1966) reported a similar relationship between exponents. Their exponent for loudnesss as a function of sound energy equalled about $80 \%$ of their exponent for loudness as a function of duration; the present data yield exponents for intensity that are approximately $70 \%$ of those for duration.

Over their linear segments, the average horizontal separation between the monaural and binaural functions in Figure 4 is approximately .5 logarithmic units. That is,

Table 1

Average Binaural-to-Monaural Loudness-Judgment Ratios for Tones at Different Sound-Pressure Levels (SPLs) and Durations

\begin{tabular}{cccccccc}
\hline \multirow{2}{*}{$\begin{array}{c}\text { SPL } \\
\text { (in dB) }\end{array}$} & \multicolumn{7}{c}{ Duration (in msec) } \\
\cline { 2 - 7 } & 16 & 32 & 64 & 128 & 256 & 512 & Mean \\
\hline 30 & 2.46 & 1.02 & 2.09 & 1.01 & 1.42 & 2.07 & 1.67 \\
40 & 0.83 & 1.21 & 1.51 & 1.28 & 1.43 & 1.8 & 1.34 \\
50 & 0.89 & 1.47 & 1.02 & 1.81 & 1.32 & 1.58 & 1.34 \\
60 & 1.39 & 1.23 & 1.2 & 1.77 & 1.61 & 2.07 & 1.54 \\
70 & 1.24 & 1.37 & 1.55 & 1.57 & 1.44 & 1.98 & 1.52 \\
Mean & 1.36 & 1.26 & 1.47 & 1.48 & 1.44 & 1.9 & 1.48 \\
\hline
\end{tabular}




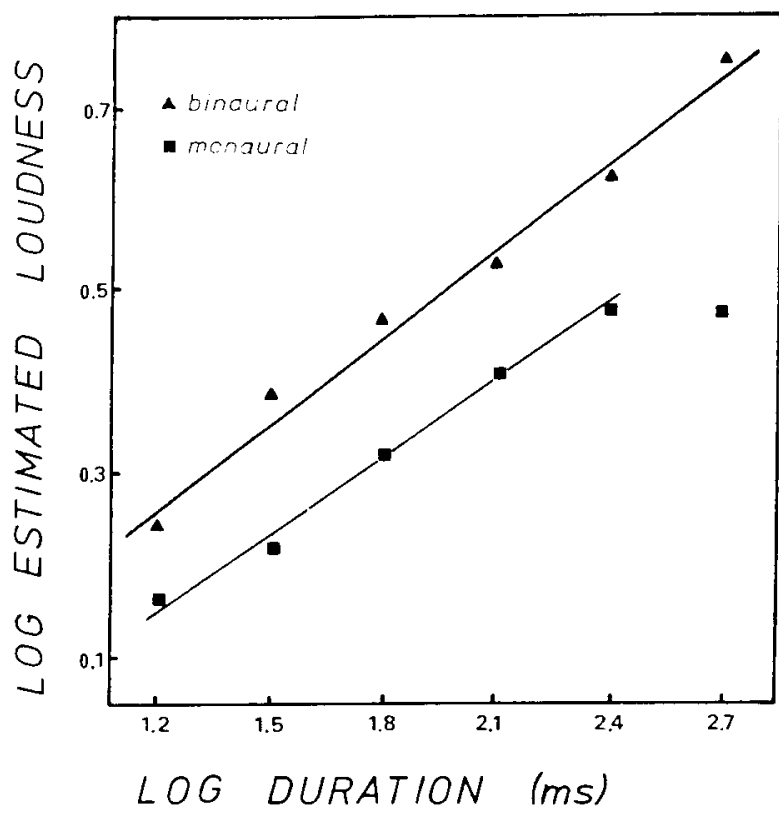

Figure 4. Binaural summation of loudness as a function of duration. Average loudness functions of binaural and monaural stimuli derived from the marginal means of the data plotted in Figures 1 and 2.

on the average, a threefold increase in the duration of a monaural tone was needed for it to appear equally as loud as a binaural tone of the same intensity. This binaural gain (the difference in log duration between equally loud monaural and binaural stimuli) entails a corresponding power-function exponent for loudness relative to duration. Given the presently derived binaural-monaural loudness ratio (of about 1.5:1), the implied exponent for loudness is about .35 . This value is fairly close to the directly derived exponents for duration as well as to the comparable loudness exponents for duration reported by J. C. Stevens and Hall (1966). Thus, loudness seems to grow approximately as the cube root of duration.

Time-intensity tradeoff assessed from the binaural gains in pressure and duration. The two indexes of binaural gain, namely, the difference in decibels and the difference in (log) duration between equally loud monaural and binaural stimuli, provide for an estimation of the timeintensity tradeoff. For equal-duration monaural and binaural tones (i.e., collapsing the duration dimension in the response matrix), the monaural tones had to be augmented by $7 \mathrm{~dB}$ for them to appear equally loud. For equal SPL monaural and binaural stimuli (i.e., collapsing the soundpressure dimension in the data matrix), the monaural tone had to be tripled in duration to sound equally loud. This yields a time-intensity trading relationship characterized by a slope of $-7 \mathrm{~dB}$ per tripling of duration; that is, for loudness to be judged equal, intensity has to be decreased by $15 \mathrm{~dB}$ for each tenfold increase in duration.

Time-intensity tradeoff assessed from loudness functions at each duration. Table 2 presents parameters of the power fits applied to the loudness functions at the different durations for monaural and binaural presentations.

This is no obvious trend in the derived exponents across either mode (monaural vs. binaural) or duration. The average is about .40 , consistent with the value derived on the basis of the marginal means. Moreover, the fits to the power functions are again excellent.

To obtain traditional time-intensity tradeoff functions, the six loudness functions were horizontally intersected at the same ordinate values for both modes of stimulation. Thus generated, one such pair of monaural and binaural trading functions for (the same) equal loudness is shown in Figure 5.

For both conditions, as stimulus duration increased, the intensity necessary to produce an equal-loudness judgment decreased. This trading relationship does not, however, obey a rule of simple reciprocity because the linear region of each function does not have a slope of -1 . The slopes, based on the five shortest durations for the monaural mode and all durations for the binaural mode, have a mean of -1.75 . On the average, then, intensity had to be decreased by $17.5 \mathrm{~dB}$ for each tenfold increase in duration. This trading relationship is very much like the one derived earlier and is quite (though not fully) consistent with those obtained by Algom and Marks (1984), Small et al. (1962), and J. C. Stevens and Hall (1966) in their studies of suprathreshold integration. Note, though, that the latter two studies used a wide-band noise as a stimulus, in contrast to the $2000-\mathrm{Hz}$ tone used here. Note, too, that although a critical duration of approximately $256 \mathrm{msec}$ characterizes the monaural data, no comparable changes are detectable in the slope of the respective binaural trading function.

Loudness functions and binaural gains assessed from the time-intensity tradeoff. The monaural and binaural trading functions in Figure 5 provide for yet another estimation of the binaural gains. Over their linear ranges, the vertical separation between the monaural and the binaural functions is about $6.7 \mathrm{~dB}$, a value virtually identical to the 7- $\mathrm{dB}$ binaural gain derived on the basis of the marginal means. Given the binaural-monaural ratio derived earlier (in the vicinity of 1.5 ) this implies a loudness function relative to SPL with an exponent of approx-

Table 2

Parameters of the Psychophysical Power Function for Loudness Relative to Sound-Pressure Level at Six Different Durations for Monaural and Binaural Listening

\begin{tabular}{cccccccc}
\hline \multirow{2}{*}{$\begin{array}{c}\text { Duration } \\
\text { (in msec) }\end{array}$} & \multicolumn{3}{c}{ Monaural } & & \multicolumn{3}{c}{ Binaural } \\
\cline { 2 - 4 } \cline { 5 - 7 } & \multicolumn{1}{c}{$b$} & $b$ & $r^{2}$ & & $a$ & $b$ & $r^{2}$ \\
\hline 16 & -.7 & .34 & .97 & & -.64 & .34 & .92 \\
32 & -.72 & .36 & .99 & & -.59 & .38 & .99 \\
64 & -.64 & .38 & .97 & & -.56 & .4 & .99 \\
128 & -.5 & .36 & .98 & & -.55 & .4 & .99 \\
256 & -.52 & .4 & .99 & & -.45 & .42 & .99 \\
512 & -.58 & .42 & .99 & & -.3 & .42 & .99 \\
Mean & & .38 & & & .39 & \\
\hline
\end{tabular}

Note- $a=$ intercept, $b=$ power-function exponent. 


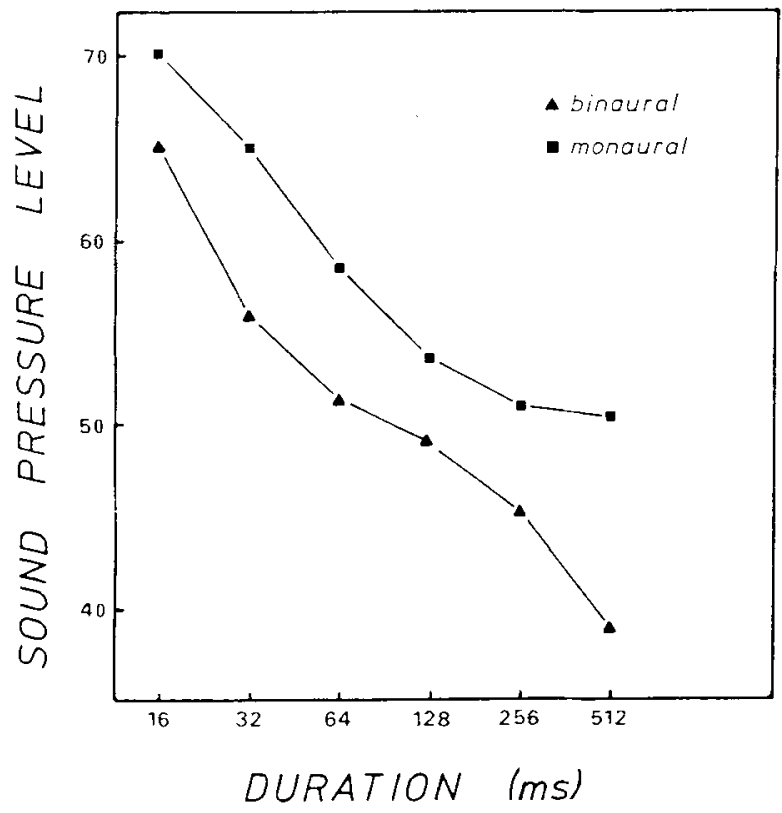

Figure 5. Equal-loudness contours giving the combinations of duration, pressure, and mode of listening (binaural vs. monaural) that produced the same subjective loudness.

imately .51. The horizontal separation of the curves-the difference in duration between equally loud monaural and binaural stimuli-gives the binaural gain in time. The trading functions indicate roughly a 2.5 -fold binaural gain. Given the corresponding 6.7- $\mathrm{dB}$ gain in pressure, this yields a time-intensity trading ratio of $-6.7 \mathrm{~dB} / 2.5 \mathrm{msec}$ (or approximately $-18 \mathrm{~dB} / 10 \mathrm{msec}$ ). Incidentally, the 2.5-fold binaural gain in duration also implies a scale for loudness which grows as the .43 power of tone duration. Clearly, then, these estimates for loudness as a function of SPL and as a function of duration, as well as the assessment of the time-intensity reciprocity, closely correspond to the respective values derived earlier on the basis of the metric properties of the data taken as a whole. Moreover, both sets of estimates, it should be recognized, were obtained independently of subjects' numerical judgments.

What is the relationship between temporal and binaural summation? The overall pattern of the response array remains strikingly uniform regardless of the type of summation tested. The rules shown to govern the binaural summation of long supercritical tones also apply to much shorter tones regardless of temporal summation that the latter undergo. Moreover, temporal summation of suprathreshold tonal stimuli follows the same course regardless of whether the tones are presented to just one ear or to both. This outcome, namely the total lack of mutual influence or interaction between the two integration processes, suggests that they are based on orthogonal, possibly identical, mechanism(s). The underlying network of integration, to be thought of as a neural organization at some high level in the auditory system, sums these types of input in an additive manner.

\section{EXPERIMENT 2 \\ TEMPORAL INTEGRATION AND BINAURAL SUMMATION OF BROAD-BAND NOISES}

\section{Method}

Subjects. Eight subjects (5 females) participated in this experiment. Their ages ranged from 19 to 32 , with a mean of 22 years. The criteria for selection were those used in Experiment 1. None of these subjects had taken part in Experiment 1, but two had previous experience in judging loudness.

Apparatus and Procedure. The production of the stimuli was identical to that used in the previous experiment, except that a General Radio 1390-B random-noise generator provided the trapezoid shaped, 1-msec onset and 1-msec offset, bursts of noise. The makeup of these stimuli and the details of the method and procedure were like those used in Experiment 1 . The set of stimuli again comprised all 60 combinations of six durations (16-512 msec), five SPLs (30-70 dB), and two modes of presentation (monaural and binaural) of white noise. The response of the headphones was essentially flat between 300 and $5000 \mathrm{~Hz}$; there were a few dips and rises that in no case exceeded $2 \mathrm{~dB}$. Each subject made four judgments per stimulus in all. Again, the method was free-magnitude estimation. The subject's task was to assign numbers in proportion to loudness.

\section{Results and Discussion}

Metric structure. Figures 6 and 7 present the factorial plots for the monaural (right ear) and binaural presentations, respectively. Both families of functions are linearly divergent, as they should be if they reflect bilinear interaction. They both pass the visual test of bilinearity obtained by spacing the stimuli in the horizontal axis according to the marginal means. Both families of functions appeared as a fan of straight lines. ${ }^{3}$ To a first approximation, then, these results imply that the subjects did use a simple multiplicative process when they estimated loudness.

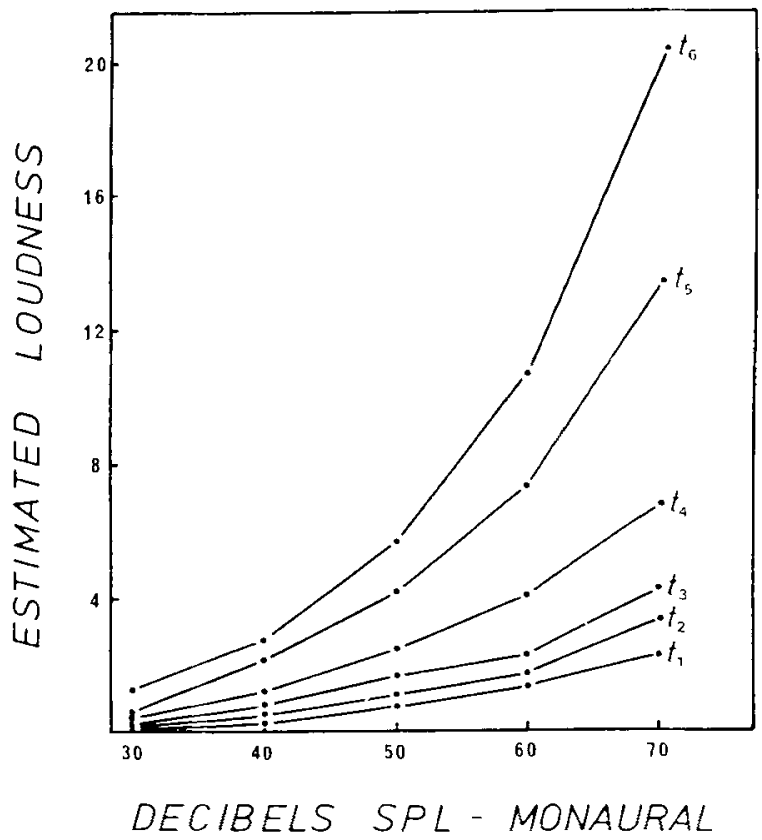

Figure 6. Monaural temporal integration of noise. Same as Figure 1, for wide-band noise bursts. 


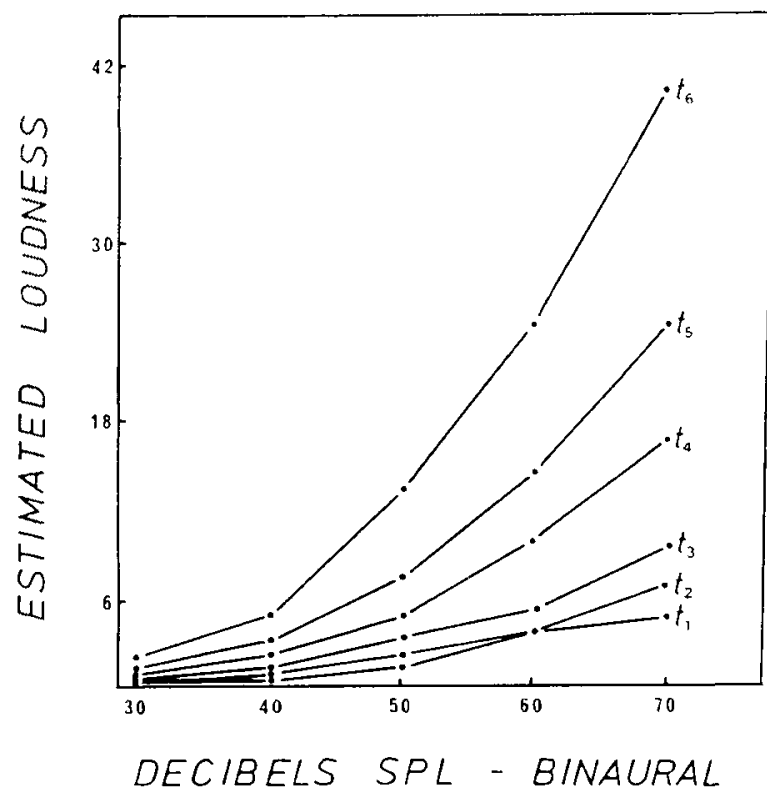

Figure 7. Binaural temporal integration of noise. Same as Figure 2, for wide-band noise bursts.

Loudness of wide-band noise as a function of pressure. Figure 8 gives the monaural and binaural loudness functions with respect to SPL, based on the marginal means of the respective response matrices. The data for both conditions appear somewhat bow-shaped, a curvature that has been noted several times before for noise (Marks, 1980; Pollack, 1951; Scharf \& Fishken, 1970).

A striking characteristic of the binaural and monaural functions, as shown in Figure 8, is the systematic change in the number of decibels separating them. The results of Irvin (1965), Marks (1980), Reynolds and S. S. Stevens (1960), Scharf (1968), Scharf and Fishken (1970), and recently, of Algom et al. (1988) showed a similar change with level for noise stimuli. At low levels, the monaural noise had to be about $4 \mathrm{~dB}$ greater than the binaural noise to be judged as loud, but this difference increased to about $9 \mathrm{~dB}$, in the present set of short noise bursts, at levels around $70 \mathrm{~dB}$. If we grant power functions to describe the growth of loudness (the exponents are .68 and .60 , respectively, for the binaural and monaural data; $r^{2}=.96$ and .98 , respectively), then the ratio of binaural to monaural loudness increases continuously with increasing SPL. By way of contrast, the data on pure tones (Experiment 1) show a decibel difference that remains roughly constant at $7 \mathrm{~dB}$ for the entire $30-70 \mathrm{~dB}$ range. ${ }^{4}$

More important to the present purpose than the form of these particular psychophysical functions is the demonstration that binaural summation of brief noise stimuli obeys exactly the same rules that govern binaural summation of much longer noise stimuli. That these brief stimuli presumably undergo a concurrent process of temporal integration does not seem to alter the course of binaural summation in any systematic fashion. Both for long noises beyond the critical duration and for brief noises below the critical duration, binaural summation is partial at low SPLs, increasing to greater summation at high SPLs. Different rules of interaural integration, then, apply to wide-band noises and to narrow-band signals, regardless of duration.

Loudness of wide-band noise as a function of duration. Figure 9 presents the loudness functions for monaural and binaural presentations with duration as the argument. The fits to the power functions are good $\left(r^{2}=\right.$ .989 for the monaural function and .995 for the binaural function). There is only a slight difference in slope $(b)$, the binaural function being a bit steeper $(b=.62$ and .65 for the monaural and binaural conditions, respectively).

Figures 8 and 9 seem to imply that the growth of loudness with either increasing pressure or increasing duration is greater for noises (present experiment) than for pure tones (Experiment 1). It is not clear why the loudness functions for duration, while following a power law, should differ for tones and noises. A possible clue comes from the examination of the time-intensity trading functions for equal loudness derived in previous studies. Typically, tones yield shallower reciprocity functions than do noises, with a slope closer to -1.0 (Algom \& Marks, 1984; see also Scharf, 1978), which implies a greater role for duration in noise.

If we take the monaural and binaural loudness functions for duration to parallel one another, an additional scale for loudness can be derived. The average horizontal separation between the functions in Figure 9 is about $.4 \mathrm{log}$

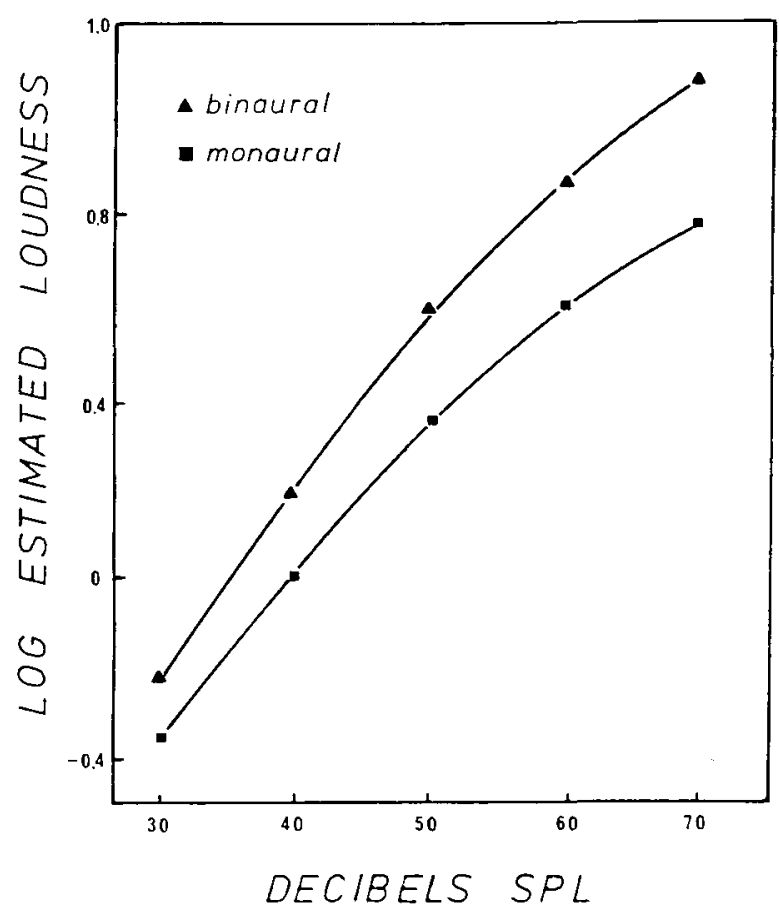

Figure 8. Binaural summation of the loudness of noises as a function of sound-pressure level (SPL). Same as Figure 3, for functions derived from the marginal means of the data plotted in Figures 6 and 7. 


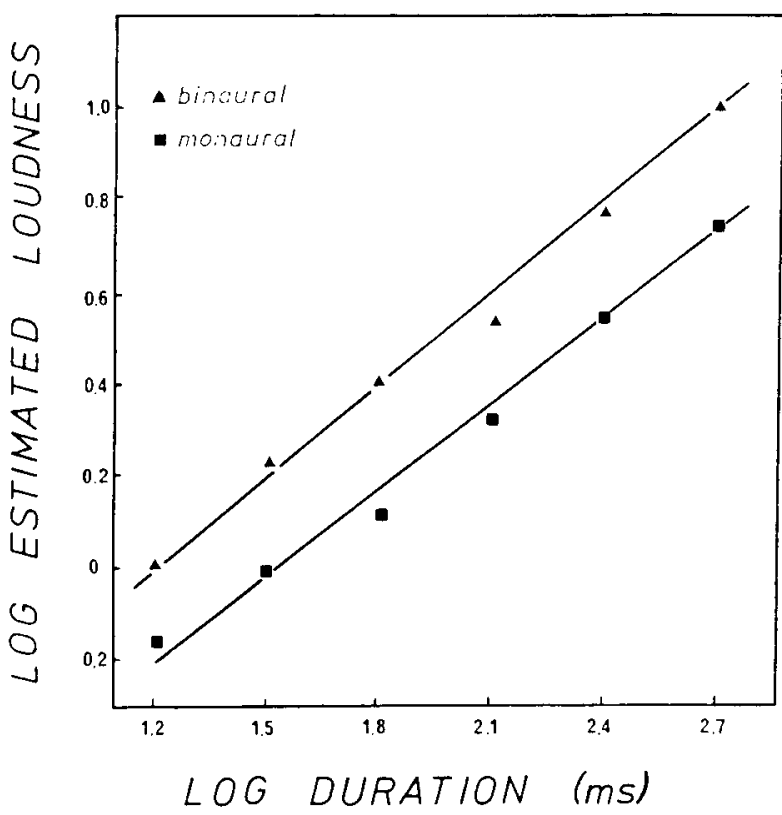

Figure 9. Binaural summation of the loudness of noises as a function of duration. Same as Figure 4 , for functions derived from the marginal means of the data plotted in Figures 6 and 7.

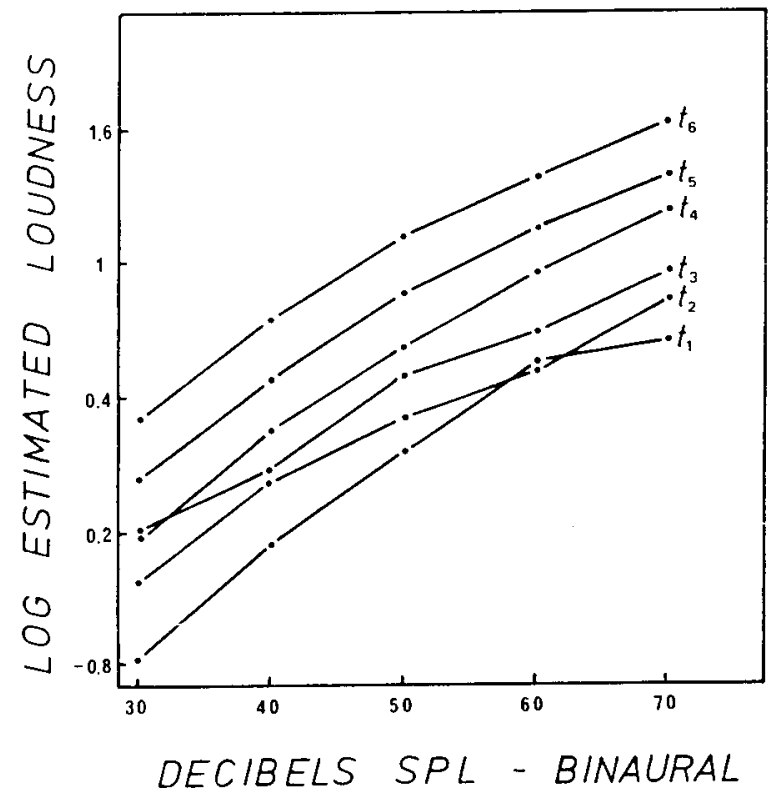

Figure 10. The growth of the loudness of noise bursts as a function of stimulus magnitude for six different durations. The data are those presented in Figure 7, plotted in double-logarithmic coordinates.

units. This binaural gain means that a 2.5 -fold increase in the duration of a monaural noise burst is needed for it to sound equally as loud as a binaural burst of the same SPL. Given an average binaural-monaural loudness ratio of 1.88 (Table 3 ), this yields a loudness function which is about the .69 power of duration.

Time-intensity tradeoff for noise. Power fits were attempted to the judgments at each duration, separately for the monaural and binaural data. Good only as a first approximation (note the curvature or bowing in the shape of the curves in the example provided in Figure 10), the fits seem, nevertheless, satisfactory for a convenient summary (Table 4).

At all durations, the exponent of the binaural function is greater than the exponent of the corresponding monaural function. The mean difference is .066 , quite consistent with the value [a difference of $.08(.68-.60)$ between binaural and monaural listening] derived earlier on the basis of the marginal means.

The log-log plots of the loudness estimates at the six durations were intersected at several arbitrary ordinate levels for both monaural and binaural listening. Figure 11 plots one such set of corresponding pairs of pressure and duration, at both monaural and binaural modes of presentations, necessary to produce an equal-loudness judgment.

There is a fundamental difference between tones and noises in the way they interact binaurally, and, consequently, in their respective courses of temporal integration. The monaural and binaural trading functions for tones were essentially parallel, reflecting a virtually identical course of temporal integration for both listening conditions. This was not so with noises: The reciprocity functions for monaural and binaural listening are nonparallel, converging at the lower right. The binaural function has a slope of approximately -1.4 , whereas the monaural function has a significantly steeper slope of around -2.0 . Clearly, the integration of monaurally presented noise stimuli follows a different time course than does the integration of binaurally presented stimuli. The vertical separation between the monaural and binaural functions decreases gradually from about $12 \mathrm{~dB}$ at the shortest du-

Table 3

Average Binaural-to-Monaural Loudness-Judgment Ratios for Noises at Different Sound-Pressure Levels (SPLs) and Durations

\begin{tabular}{cccccccc}
\hline SPL & \multicolumn{7}{c}{ Duration (in msec) } \\
\cline { 2 - 7 } (in dB) & 16 & 32 & 64 & 128 & 256 & 512 & Mean \\
\hline 30 & 1.37 & 1.68 & 1.8 & 0.83 & 1.27 & 1.45 & 1.4 \\
40 & 0.81 & 2.07 & 1.75 & 1.43 & 2.02 & 2.52 & 1.76 \\
50 & 0.7 & 1.7 & 2.8 & 1.39 & 1.45 & 2.3 & 1.89 \\
60 & 1.99 & 1.28 & 2.17 & 2.70 & 2.53 & 2.52 & 2.19 \\
70 & 1.96 & 2.10 & 2.53 & 2.55 & 2.26 & 1.71 & 2.18 \\
Mean & 1.56 & 1.76 & 2.21 & 1.78 & 1.9 & 1.75 & 1.88 \\
\hline
\end{tabular}

Table 4

Parameters of the Psychophysical Power Function for Loudness Relative to Sound-Pressure Level at Six Different Durations for Monaural and Binaural Listening

\begin{tabular}{cccccccc}
\hline \multirow{2}{*}{$\begin{array}{c}\text { Duration } \\
\text { (in msec) }\end{array}$} & \multicolumn{3}{c}{ Monaural } & & \multicolumn{3}{c}{ Binaural } \\
\cline { 2 - 4 } \cline { 5 - 7 } & \multicolumn{1}{c}{$b$} & $\boldsymbol{r}^{2}$ & & \multicolumn{1}{c}{$\boldsymbol{a}$} & \multicolumn{1}{c}{$b$} & $\boldsymbol{r}^{2}$ \\
\hline 16 & -1.89 & $\mathbf{0 . 6 8}$ & 0.92 & & -1.78 & 0.72 & 0.95 \\
32 & -1.45 & $\mathbf{0 . 5 6}$ & 0.95 & & -1.3 & 0.6 & 0.98 \\
64 & -1.32 & 0.56 & 0.97 & & -1.06 & 0.58 & 0.98 \\
128 & -1.05 & 0.56 & 0.96 & & -1.4 & 0.76 & 0.96 \\
256 & -1.12 & 0.66 & 0.96 & & -0.92 & 0.68 & 0.98 \\
512 & -0.7 & 0.56 & 0.99 & & -0.6 & 0.64 & 0.98 \\
Mean & & 0.60 & & & 0.66 & \\
\hline
\end{tabular}

Note- $a=$ intercept, $b=$ power-function exponent. 


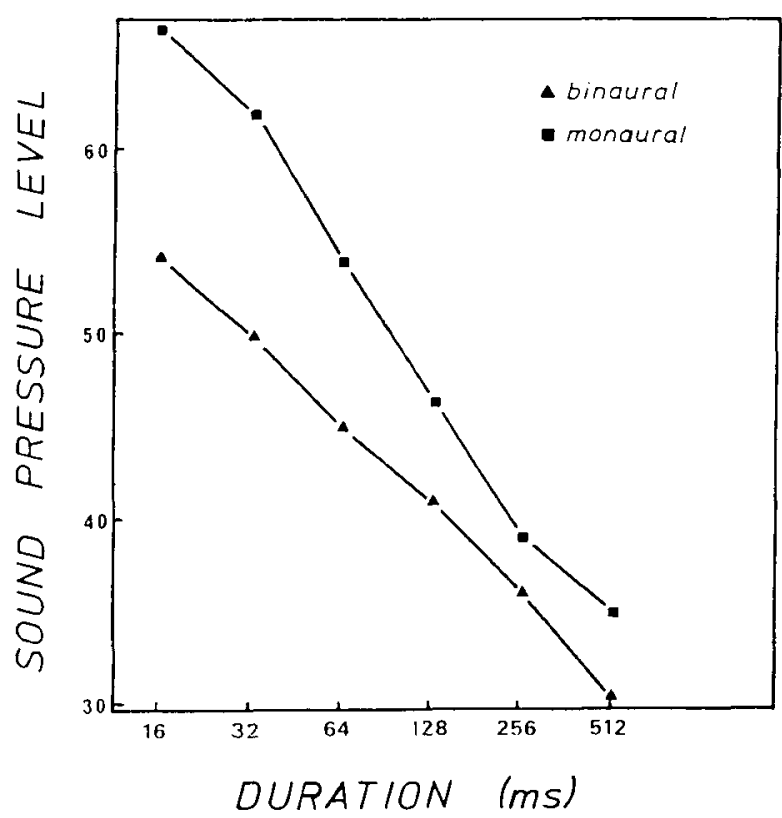

Figure 11. Equal-loudness contours for noise, giving the combinations of duration, pressure, and mode of listening (binaural vs. monaural) that produced the same subjective loudness.

rations to about $4 \mathrm{~dB}$ at a duration of $.5 \mathrm{sec}$. These data for noise, then, suggest a nonconstant binaural gain in decibels at the different stimulus durations.

Perhaps the simplest way to interpret these results is to relate them to the rather widely documented data on the growth of loudness for noise. Regardless of its form (particularly whether or not a power function), the loudness of a wide-band noise increases with increasing SPL more rapidly under binaural than under monaural listening. Given that binaural and monaural loudness varies the same way as a function of duration (see Figure 9), the different rates of growth with increasing sound pressure must result in different values of the time-intensity tradeoff, as Figure 11 clearly demonstrates.

The most important empirical outcome of this experiment, then, is the different slopes demonstrated for the temporal integration of monaural and binaural noise signals. This contrasts with the results obtained for tones (Experiment 1) and for threshold-level noises (Babkoff \& Algom, 1976) collected under similar conditions.

\section{GENERAL DISCUSSION}

\section{Derivation of Equal-Loudness Contours for Time-Intensity Combinations}

Despite some variability, the data clearly demonstrate the general nature of temporal summation for suprathreshold loudness: loudness increases with both increasing duration and increasing intensity (then, beyond the critical duration, it becomes relatively independent of duration). Thus, at short durations, the data imply that loudness $(L)$ grows as a power function of duration $(d)$ :

$$
L=c_{1} t^{d} .
$$

When the same data are plotted in terms of stimulus energy $(I)$, power fits are again able to describe the function relationship (at least to a good first-order approximation):

$$
L=c_{2} I^{s} .
$$

Following Marks (1974) and J. C. Stevens and Hall (1966), the relationships given by Equations 1 and 2 can be combined into a single statement that includes the effects of both energy and duration. The general formula for loudness below the critical duration, then, can be written

$$
L=c t^{d} I^{z} \text {. }
$$

From Equation 3, another simple relationship can be secured, namely, the combinations of energy and duration necessary to produce any constant level of loudness:

$$
I t^{a}=C,
$$

where $a=d / g$. The relationship expressed by Equation 4 is, of course, Garner's well-known formula for relating time and energy, already given in the introduction.

Of major interest here is the question of how the empirical values, derived under the different experimental conditions, map onto the parameters depicted by Equations 1-4. In particular, do different values apply to monaural and binaural modes of listening? How does the spectral distribution of sounds affect the functional relationships under consideration? Given the model depicted by Equation 3, the loudness equations for monaural $(m)$ and binaural $(b)$ listening, respectively, can be written

$$
L_{m}=c_{m} t^{d_{m} I_{m}}
$$

and

$$
L_{b}=c_{b} t^{d_{b}} I^{s_{b}} \text {. }
$$

For the sake of simplicity, we assume that the two ears are equally sensitive, so that a single equation suffices to describe monaural hearing (cf. Marks, 1978). Given these equations for monaural and binaural listening, binaural stimulation below the critical duration will show perfect binaural summation at all SPLs only if $d_{b}=d_{m}, g_{b}=g_{m}$, and $c_{b} / c_{m}=2$. Given that these are true, an immediate corollary shows that the slopes of the time-intensity trading functions should be the same for monaural and binaural listening. That is, we expect parallel equalloudness contours, or that $a_{b}=a_{m}$ (Equation 4).

\section{Binaural and Temporal Integration for Tones}

The data for pure tones (Experiment 1) satisfy the equalexponent, equal reciprocity-slope requirements but they fall short of full binaural summation in that $c_{b} / c_{m}<2$. Binaural summation is constant, yet is only partial at about $7 \mathrm{~dB}$. The average values of $d$ and $g$ (relative to sound energy) were .29 and .20 , respectively. That is, $d$ is approximately 1.5 times larger than $g$. Equation 3 thus can be specified as 


$$
L=c t^{29} I^{2},
$$

or, if we take the correct value of $g$ to be .3 (the sone function), it can be rewritten

$$
L=c t^{435} I^{3} \text {. }
$$

Ideally, the equal-loudness contours should have a slope of around $1.5(\cong .29 / .2$ or $.435 / .37)$. The slope derived on the basis of the tradeoff functions turned out to be about 1.7. Thus, Equation 4 can be rewritten

$$
I t^{1.5}=C,
$$

implying that the exponent for the psychophysical power function should be 1.5 times larger for duration than for sound energy. More important to the present purpose than the particular numerical values is the demonstration that, for pure tones, the temporal integration of monaurally and binaurally presented stimuli follow the same course. Consequently, binaural summation of short sinusoidal signals does not depend on their duration. (The binaural gain was constant across the different-duration stimuli.) The lack of a binaural $\times$ temporal interaction in loudness implies that neither process exerts any systematic influence on the other. Binaural summation of short signals, the loudness of which is affected by duration, obeys the same rule of summation that governs the binaural summation of longer signals, the loudness of which is independent of duration.

\section{Binaural and Temporal Integration for Noises}

For noises, the results are more complicated. The parameters differ for monaural and binaural hearing such that $g_{b} \neq g_{m}$ and, of course, $c_{b} / c_{m}$ is not constant. Interestingly, however, $d_{b}=d_{m}$, which means that the psychophysical function for duration is the same for monaural and binaural listening. Given that $d_{b}=d_{m}$ and $g_{b} \neq g_{m}$, it follows that $a_{b} \neq a_{m}$. Indeed, the timeintensity trading functions (see Equation 4) differ for monaural and binaural listening. They can be respectively specified

$$
I_{m} t^{2}=C_{m}
$$

and

$$
I_{b} t^{1.4}=C_{b},
$$

where $C_{b}$ is set to equal $C_{m}$.

Clearly, temporal integration of noises bursts differs for monaurally and binaurally presented stimuli. For both modes of stimulation, time plays a more prominent role than does sound energy, but the monaural trading function has a much steeper slope. As a result, binaural summation decreases as duration increases. For noise bursts, then, there is an interaction between temporal and binaural integration.

\section{Temporal Summation versus Binaural Summation}

Does the obtained interaction imply an authentic influence of one integration process on the other? Not necessarily. For long-duration wide-band noise stimuli, lying well beyond the limit for temporal integration, binaural summation has already been shown to increase with increasing level (e.g., Irvin, 1965; Marks, 1980; Reynolds \& S. S. Stevens, 1960; Scharf \& Fishken, 1970). Given the time-intensity tradeoff for constant loudness, shorter stimuli must be more energetic. And, to be sure, binaural summation is greater for these stimuli than for longer (hence softer) ones. That different courses of temporal summation apply to monaural and binaural listening is an important finding first reported here. However, it basically reflects the different rates of growth for monaural and binaural loudness (of wide-band noise), rather than any genuine influence of temporal integration on binaural summation. This lack of mutual influence becomes, therefore, a fact to be fitted into a complete theory of loudness processing. 5

\section{Cognitive Algebra of the Processing of Temporally Integrated Loudness}

A unique and novel feature of the present study is the explicit establishment of the underlying metric structure for temporal summation. Traditional measurement solutions (cf. Algom \& Babkoff, 1984; J. C. Stevens, 1976) assumed that (1) subjects were in fact judging loudness, and (2) their numerical responses provided a valid measure of loudness. Both assumptions are risky and need empirical justification. This is particularly true of auditory temporal integration, in which a major theoretical effort is aimed at reconciling the linear (or close to linear) energy integration produced by the system with the equally demonstrable fact of a nonlinear relationship between sound intensity and loudness (e.g., the sone scale; Zwislocki, 1969; see also the review of theories by Algom \& Babkoff, 1984). Consequently, it is not always prima facie clear which set of values to call loudness (cf. Marks, 1979b). However, even if we grant that the output from supraliminal temporal processing does correspond to loudness, the question still remains whether the putative numerical ratios represent actual ratios of loudness. Hence, treating the subjects' magnitude estimates as the true scale values to be integrated into the prescribed psychological equation (such as the classic multiplicative model suggested for temporal integration) may be ambiguous or even misleading. It is the opinion of the present authors that failure to validate the scale values under concern satisfactorily has adversely affected the work on temporal summation.

The logic behind the present analysis owes much to Anderson's $(1981,1982)$ theory of functional measurement. In this analysis, we argue for the explicit determination of the integration function that combines separate stimulus components into a unitary response. Besides providing the explicit "cognitive algebra" used when people judge the loudness of differently shaped supraliminal signals (i.e., establishing the underlying metric structure for temporal summation), the multiplicative model established here plays a vital role in the derivation of the psychophysical functions as well. Indeed, this model provides the needed criterion to validate the overt numerical estimates (see Anderson, 1981, for details of the relevant theorems). 


\section{REFERENCES}

Algom, D. (1979). Auditory temporal integration: Detection versus discrimination. Unpublished doctoral dissertation. Bar-Ilan University, Ramat Gan, Israel.

Algom, D., Adam, R., \& Cohen-Raz, L. (1988). Binaural summation and lateralization of transients: A combined analysis. Journal of the Acoustical Society of America, 84, 1302-1315.

Algom, D., BABKoff, H. (1978). Discrimination of equal-energy, equally detectable auditory stimuli. Psychological Research, 40, 149-157.

Algom, D., BABKoFf, H. (1984). Auditory temporal integration of threshold: Theories and some implications of current research. In W. D. Neff (Ed.), Contributions to sensory physiology (Vol. 8, pp. 131-159). New York: Academic Press.

ALGOM, D., BABKoFF, H., \& BEN-URIAH, Y. (1980). Temporal integration and discrimination of equally detectable equal-energy stimuli: The effect of frequency. Psychological Research, 42, 305-318.

ALGOM, D., \& CoHEN-RAZ, L. (1984). Visual velocity input-output functions: The integration of distance and duration onto subjective velocity. Journal of Experimental Psychology: Human Perception \& Performance, 10, 486-501.

Algom, D., \& MarKs, L. E. (1984). Individual differences in loudness processing and loudness scales. Journal of Experimental Psychology: General, 113, 571-593.

Anderson, N. H. (1974). Algebraic models in perception. In E. C. Carterette \& M. P. Friedman (Eds.), Handbook of perception: Vol. 2. Psychophysical judgment and measurement (pp. 215-298). New York: Academic Press.

ANDERSON, N. H. (1981). Foundations of information integration theory. New York: Academic Press.

Anderson, N. H. (1982). Methods of information integration theory. New York: Academic Press.

BABKoff, H., \& ALGOM (Gombosh), D. (1976). Monaural and binaural temporal integration of noise bursts. Psychological Research, 39, 137-145.

BRINDLEY, G. S. (1960). Physiology of the retina and visual pathway. London: Arnold.

Causeè, R., \& Chavasse, P. (1942). Différences entre le seuil de l'audition binauriculaire et le seuil monauriculaire en function de la fréquence. Comptes Rendus de la Société de Biologie, 86, 301-302.

CHOcholle, R. (1962). Les effects des interactions interaurales dans l'audition. Joumal de Psychologie Normale et Pathologique, 59, 255-282.

Ekman, G. (1956). Discriminal sensitivity on the subjective continuum. Acta Psychologica, 12, 233-243.

GARNER, W. R. (1947). Effect of frequency spectrum on temporal integration in the ear. Joumal of the Acoustical Society of America, 19, 808-815.

GARNER, W. R., \& Miller, G. A. (1947). The masked threshold of pure tones as a function of duration. Journal of Experimental Psychology, 37, 293-303.

Hellman, R. P., \& ZWISLOCKI, J. J. (1963). Monaural loudness function at $1000 \mathrm{cps}$ and interaural summation. Journal of the Acoustical Society of America, 35, 856-865.

Hughes, J. W. (1938). The monaural threshold: Effect of a subliminal contralateral stimulus. Proceedings of the Royal Society, London, 124b, 406-420.

IRWIN, R. J. (1965). Binaural summation of thermal noises of equal and unequal power in each ear. American Joumal of Psychology, 78, $57-65$.

JANkovic, I. N., CRoss, D. V. (1977, April). On the binaural additivity of loudness. Paper presented at the meeting of the Eastern Psychological Association, Boston.

Levelt, W. J. M., Riemersma, J. B., \& Bunt, A. A. (1972). Binaural additivity of loudness. British Journal of Mathematical \& Statistical Psychology, 25, 51-68.

MARKs, L. E. (1974). Sensory processes: The new psychophysics. New York: Academic Press.

MARKs, L. E. (1978). Binaural summation of the loudness of pure tones. Joumal of the Acoustical Society of America, 64, 107-113.
MarKs, L. E. (1979a). Sensory and cognitive factors in judgments of loudness. Journal of Experimental Psychology: Human Perception \& Performance, 5, 426-443.

MaRKs, L. E. (1979b). A theory of loudness and loudness judgments. Psychological Review, 86, 256-285.

MarKs, L. E. (1980). Binaural summation of loudness: Noise and two tone complexes. Perception \& Psychophysics, 27, 489-498.

MarKs, L. E. (1987). Binaural versus monaural loudness: Supersummation of tone partially masked by noise. Journal of the Acoustical Society of America, 81, 122-128.

MCFADDEN, D. (1975). Duration-intensity reciprocity for equal loudness. Journal of the Acoustical Society of America, 57, 702-704.

Miller, C. A. (1948). Perception of short bursts of noise. Journal of the Acoustical Society of America, 20, 160-170.

Penner, M. J. (1978). A power law transformation resulting in a class of short-term integrators that produce time-intensity trades for noise bursts. Jourmal of the Acoustical Society of America, 63, 195-201.

Pollack, I. (1951). On the measurement of the loudness of white noise. Journal of the Acoustical Society of America, 23, 654-657.

ReYNolds, G. S., Stevens, S. S. (1960). Binaural summation of loudness. Joumal of the Acoustical Society of America, 32, 1337-1344.

SCHARF, B. (1968). Binaural loudness summation as a function of bandwidth. In Y. Kohasi (Ed.), Reports of the 6th International Congress on Acoustics (Vol. 1, pp. 25-28). Tokyo: Marazen A-3-5.

SCHARF, B. (1969). Dichotic summation of loudness. Journal of the Acoustical Society of America, 45, 1193-1205.

Scharf, B. (1978). Loudness. In E. C. Carterette \& M. P. Friedman (Eds.), Handbook of perception: Vol. 4. Hearing (pp. 187-242). New York: Academic Press.

SCHARF, B., \& FishKeN, D. (1970). Binaural summation of loudness: Reconsidered. Journal of Experimental Psychology, 86, 374-379.

Shaw, W. A., Newman, E. G., Hirsh, I. J. (1947). The difference between monaural and binaural thresholds. Journal of Experimental Psychology, 37, 229-242.

Small, A. M., JR., Brandt, J. R., \& Cox, P. C. (1962). Loudness as a function of signal duration. Journal of the Acoustical Society of America, 34, 513-514.

STEVENS, J. C. (1976). Equal-sensation functions generated by the method of magnitude estimation. Journal of the Acoustical Society of America, 59, 473-474.

SteVens, J. C., \& Hall, J. W. (1966). Brightness and loudness as a function of stimulus duration. Perception \& Psychophysics, 1, 319-327.

STEVENS, S. S. (1956). The direct estimation of sensory magnitudesloudness. American Journal of Psychology, 69, 1-15.

Stevens, S. S., Greenbaum, H. B. (1966). Regression effect in psychophysical judgment. Perception \& Psychophysics, 1, 439-446.

Watson, C. S., \& GenGEL, R. W. (1969). Signal duration and signal frequency in relation to auditory sensitivity. Journal of the Acoustical Society of America, 46, 989-997.

ZWISLOCKI, J. J. (1969). Temporal summation of loudness: An analysis. Journal of the Acoustical Society of America, 46, 431-441.

\section{NOTES}

1. It is often possible to test the model analytically by applying analysis of variance (ANOVA) to the data (Anderson, 1974, 1982). Legitimate application of ANOVA, however, requires that the data have reasonably uniform variance, a condition that typically does not hold with magnitude estimates. By contrast, functional dependencies between the means and the standard deviations of magnitude estimates, violating assumptions of ANOVA, are often encountered in psychological research (cf. Algom \& Cohen-Raz, 1984; Marks, 1978, 1980). As a general rule, the standard deviations of these estimates increase nearly in proportion to the means of the estimates-a relationship that is sometimes called Ekman's law (Ekman, 1956). This phenomenon characterized all of the present data sets. Nonetheless, we attempted an application of ANOVA to the binaural data (Figure 2) - the set coming closest to displaying reasonably (though not fully) uniform variance. The results confirmed the conclusions drawn from the graphic display. There was a highly significant pressure $x$ duration interaction $[F(20,180)=2.60$, 
$p<.01]$, the better part of which (78\%) appeared in the bilinear component. The bilinear component was highly significant $[F(1,180)=13.9$, $p<.01]$, whereas the remainder of the interaction was insignificant $[F(19,180)=1.89, p>.05]$. A similar ANOVA applied to the monaural data yielded a nonsignificant interaction $[F(12,180)=1.11, p>.05]$. As noted earlier, however, although straightforward application of ANOVA is questionable, the visual appearance of the data bears out the predictions of the multiplicative model quite convincingly.

2. In fact, three simple possibilities exist: (1) Loudness is added linearly across the two ears, but this complete binaural summation corresponds to a 7-dB increase in SPL; (2) summation is perfect across the two ears, but the values of loudness that are summed in the binaural system differ from sones and are rather commensurate with the empirically derived power-function exponents of around .4; or (3) loudness should be counted in sones (i.e., the present scale approximates the sone function), and the 7-dB binaural gain obtained here indicates less than complete loudness summation. One way to assess these alternatives is to derive their implications fully and them compare them with the empirically obtained values. Thus, because linear summation means that binaural loudness is twice monaural loudness, a binaural gain $(N)$ entails a corresponding power-function exponent, which equals $\log 2 /(N / 20)$. A 7 -dB binaural gain-taken to correspond to complete summation-implies an exponent of .86 . This value is not only incompatible with the empirically derived exponents (at around .4) and the sone scale, but also with the great bulk of loudness exponents reported in the literature (cf. Marks, 1974). Conversely, given a psychophysical scale for loudness which is a .4 power of pressure and complete binaural summation, one can calculate the implied binaural gain (the difference in decibels between equally loud monaural and binaural stimuli). The above assumptions yield a gain of around $15 \mathrm{~dB}$, a value that is clearly at odds both with the empirically obtained ratio of $7 \mathrm{~dB}$ and with previously obtained estimates. We must, perforce, reject the first two alternatives above as possible explanations of the present data.

3. The appropriate ANOVAs yielded overall interaction terms that were highly significant $[F(20,140)=1.88$ for the monaural data and 1.98 for the binaural data, $p<.01$ in both cases]. As noted above, however, these are hardly tests of bilinearity because magnitude estimation tends to yield nonuniform variances. Most important, however, the divergent bilinear interactions are clearly evident upon visual inspection of the results.

4. That the binaural-to-monaural loudness ratio grows larger with increasing SPL can be gleaned from inspection of the marginal means vis- à-vis intensity (the last column in Table 3). A log-log plot of this ratio as a function of SPL yields a straight line (fitted by least squares) with a slope of .096. It appears, therefore, that the binaural-to-monaural loudness ratio increases as a power function of SPL with an exponent of .096 . Recall that the difference in exponents between the binaural and the monaural loudness functions (relative to SPL) comes quite close to this value. Thus, there is a good agreement between these two ways of looking at the binaural summation of the loudness of noises (cf. Reynolds \& S. S. Stevens, 1960). By contrast, no obvious trend in the binaural-tomonaural loudness ratios is evident across the different durations.

5. An important quantitative property of the data deserves mention. Both for tones and for noises, the slopes $(a)$ of the reciprocity functions are substantially different from what is usually found for threshold-level stimuli. For both types of signals, a given change in intensity could be offset by a smaller relative change in duration to maintain a constant loudness (supersummation). Yet in order to maintain a just-detectable sensation of loudness, a given change in intensity must be offset by either an equally large change in duration (complete summation, tones) or a larger relative change in duration (partial summation, noises) (Algom \& Babkoff, 1984; Babkoff \& Algom, 1976; Marks, 1974). Why should the nature of the time-intensity tradeoff differ for threshold and higher levels? It is tempting to consider the possibility that the difference is related to the synthetic versus the analytic characteristics of the respective processes. Thus, it may be argued that equal-energy, but differently packaged (with respect to duration and intensity), sounds are equally detectable because they appear perceptually equal. At superthreshold levels, on the other hand, although it is possible to maintain equal loudness, the different time-intensity configurations can be readily analyzed. Brindley (1960) has dubbed these two kinds of operations as Class A and Class B, respectively. Appealing as this explanation might seem, it certainly is incorrect. We (Algom, 1979; Algom \& Babkoff, 1978; Algom, Babkoff, \& Ben-Uriah, 1980) have shown that even at threshold, equal-energy, equally detectable stimuli are nevertheless clearly distinguishable from one another. Rather, the present data point toward the possibility that the variation in the magnitude of the factor $a$ is caused by differences in intensity processing between threshold and higher level stimuli (but scaling of duration remains relatively constant). Be that as it may, this again is a fact to be incorporated into a general theory of loudness or auditory integration.

(Manuscript received August 9, 1988; revision accepted for publication January 23, 1989.)

\title{
Announcement
}

\author{
Change in Editorship \\ Psychobiology
}

The Publications Committee of the Psychonomic Society take pleasure in announcing that Paul

E. Gold, University of Virginia, has accepted the editorship of Psychobiology, beginning in 1990. 